\footnotetext{
JURNAL CEMERLANG: Pengabdian pada Masyarakat

P-ISSN 2654-4741 / E-ISSN 2655-7894

Vol. 2, No. 2, Juni 2020, 121 - 132

DOI: https://doi.org/10.31540/jpm.v2i2.817

PENERBIT: LP4MK STKIP PGRI LUBUKLINGGAU
}

\title{
PELATIHAN PENGGUNAAN PROGRAM VISIO UNTUK PEMBELAJARAN DAN ADMINISTRASI SEKOLAH DI SMK NEGERI 1 GELUMBANG
}

\author{
Misdalina, Rohana, Ali Syahbana, Ety Septiati, Tanzimah, \\ Eka Fitri Puspa Sari \\ Universitas PGRI Palembang, Indonesia \\ Email: syahbanaumb@yahoo.com
}

\begin{abstract}
ABSTRAK
Kemajuan ilmu pengetahuan dan teknologi yang begitu pesat di era globalisasi berimbas pula pada pentingnya seorang guru dan tenaga kependidikan dalam meningkatkan kinerja dan kemampuan mereka sehingga terwujud keprofesionalan yang sesungguhnya. Guru maupun tenaga kependidikan mesti membekali diri mereka dengan pengetahuan yang dapat menunjang pekerjaan mereka dengan baik, salah satunya adalah kemampuan di bidang teknologi informasi. Untuk itulah perlunya guru dan tenaga kependidikan untuk selalu mengikuti pelatihan/bimbingan tentang program-program aplikasi komputer yang dapat menunjang pekerjaannya, salah satunya adalah Microsoft Visio. Kelebihan yang dimiliki aplikasi ini adalah tools-tools nya sangat mudah dipahami, cara penggunaannya yang mudah, lebih banyak pilihan gambarnya, gambar 3 dimensi cukup menarik, bisa ditambah dengan add-ins. Sehubungan dengan hal tersebut, Program Studi Pendidikan Matematika Universitas PGRI Palembang melaksanakan kegiatan Pengabdian Pada Masyarakat (PPM) yang dikemas dalam bentuk pelatihan tentang penggunaan program Visio untuk pembelajaran dan administrasi sekolah. Kegiatan dilaksanakan dalam 3 tahap: persiapan, pelaksanaan dan refleksi. Dari kegiatan tersebut telah dihasilkan modul praktikum dan respon yang positif dari peserta, sehingga kegiatan ini sangat bermanfaat dan diharapkan dapat dilaksanakan kembali.
\end{abstract}

\section{ABSTRACT}

The rapid progress of science and technology in the era of globalization has also impacted on the importance of a teacher and education staff in improving their performance and abilities so as to realize true professionalism. Teachers and education staff must equip themselves with knowledge that can support their work well, one of which is the ability in the field of information technology. For this reason the need for teachers and education personnel to always follow training / guidance on computer application programs that can support their work, one of which is Microsoft Visio. The advantages of this application are that the tools are very easy to understand, how to use them easily, more choices of images, 3-dimensional images are quite interesting, can be added with add-ins. In connection with this, the Mathematics Education Study Program of the University of PGRI Palembang carries out Community Service Activities (PPM) which are packaged in the form of training on the use of the Visio program for learning and school administration. Activities carried out in 3 stages: preparation, implementation and reflection. From these activities practical modules and positive responses from the participants have been produced, so this activity is very useful and is expected to be carried out again. 


\author{
JURNAL CEMERLANG: Pengabdian pada Masyarakat \\ P-ISSN 2654-4741 / E-ISSN 2655-7894 \\ Vol. 2, No. 2, Juni 2020, $121-132$ \\ DOI: https://doi.org/10.31540/jpm.v2i2.817 \\ PENERBIT: LP4MK STKIP PGRI LUBUKLINGGAU
}

KEYWORDS

Microsoft Visio, Pembelajaran, Administrasi

Microsoft Visio, Learning, Administration
ARTICLE HISTORY

Received 30 December 2019

Revised 15 May 2020

Accepted 17 May 2020

CORRESPONDENCE Ali Syahbana@ syahbanaumb@yahoo.com

\title{
PENDAHULUAN
}

Peraturan Menteri Pendidikan Nasional Republik Indonesia nomor 16 tahun 2007 menyebutkan bahwa "guru harus memiliki empat kompetensi utama yaitu pedagogik, kepribadian, sosial, dan professional". Agar dapat memenuhi tuntutan tersebut seorang guru seyogyanya dapat meningkatkan kompetensinya secara terus-menerus, sehingga dapat menjalankan perannya dalam mengemban tanggung-jawab secara profesional. Pengembangkan profesional guru memiliki peran penting dalam menyampaikan informasi, melatih keterampilan dan membimbing belajar siswa sehingga para guru dituntut memiliki kualifikasi dan kompetensi tertentu agar proses belajar dan pembelajaran dapat berlangsung secara efektif dan efisien. Kemajuan ilmu pengetahuan dan teknologi (IPTEK) yang begitu pesat di era globalisasi berimbas pula pada pentingnya seorang guru dalam meningkatkan kinerja dan kemampuan mereka sehingga terwujud keprofesionalan yang sesungguhnya.

Terdapat beberapa permasalahan yang muncul terkait kompetensi dan profesionalisme guru. Dua diantaranya disajikan pada Tabel 1 berikut:

\section{Tabel 1. Masalah pendidikan dan rekomendasinya}

\begin{tabular}{|c|c|}
\hline Masalah & Rekomendasi \\
\hline $\begin{array}{l}\text { Guru belum memahami dan } \\
\text { belum banyak mengetahui } \\
\text { teori, metode, dan teknik } \\
\text { mengajar }\end{array}$ & $\begin{array}{l}\text { Pemerintah daerah mengaktifkan KKG, K3S, MKKS, dan } \\
\text { MGMP budaya belajar dan budaya berbagi ilmu sesama guru } \\
\text { dapat tumbuh. } \\
\text { Pemerintah daerah mendorong guru untuk pro aktif mencari, } \\
\text { mengikuti, bahkan mengadakan pelatihan atau hal-hal yang } \\
\text { dapat memperkaya teori, metode, dan teknik mengajar. }\end{array}$ \\
\hline $\begin{array}{l}\text { Kemampuan penguasaan IT } \\
\text { masih rendah }\end{array}$ & $\begin{array}{l}\text { Pemerintah daerah memberikan pelatihan IT secara berkala } \\
\text { kepada guru-guru melalui KKG atau MGPM dengan bekerja } \\
\text { sama dengan berbagai tenaga atau relawan ahli IT atau guru- } \\
\text { guru IT. }\end{array}$ \\
\hline
\end{tabular}

Sumber: https://npd.kemdikbud.go.id/?appid=rekomendasi 


\section{JURNAL CEMERLANG: Pengabdian pada Masyarakat \\ P-ISSN 2654-4741 / E-ISSN 2655-7894 \\ Vol. 2, No. 2, Juni 2020, $121-132$ \\ DOI: https://doi.org/10.31540/jpm.v2i2.817 \\ PENERBIT: LP4MK STKIP PGRI LUBUKLINGGAU}

Dari dua permasalahan tersebut, tentunya guru maupun tenaga kependidikan mesti membekali diri mereka dengan pengetahuan yang dapat menunjang pekerjaan mereka dengan baik, salah satunya adalah kemampuan di bidang IT.

Urgensi peningkatan kemampuan TIK guru menurut Wijayanti (2011) adalah: 1) TIK dapat digunakan untuk membantu pekerjaan administratif (word processor \& Kebutuhan Wajib Tingkat Dasar, Spreadsheet), 2) TIK dapat digunakan untuk membantu mengemas bahan ajar (Multimedia) Kebutuhan Tingkat Menengah, 3) TIK dapat digunakan untuk membantu proses manajemen pembelajaran (elearning, Kebutuhan Tingkat Lanjut, dan lain-lain), 4) TIK dapat digunakan untuk dukungan teknis dan meningkatkan pengetahuan agar dapat mewujudkan self running creation (antivirus, tools, jaringan, internet, dan lainlain).

Apalagi untuk SMK, para guru harus selalu menambah wawasan pengetahuan sesuai dengan perkembangan teknologi. Komputerisasi dalam kegiatan belajar-mengajar di sekolah menuntut seorang pengajar untuk memiliki kemampuan di bidang komputer juga. Pembuatan gambar ilustrasi untuk media pembelajaran dan soal juga memberikan kesulitan tersendiri bagi tenaga pengajar terlebih bagi mereka yang belum bisa menguasai teknis keterampilan menggambar dengan menggunakan komputer. Hal tersebut merupakan hal yang baru bagi para pengajar, terutama pengajar senior, karena sudah terbiasa melakukan kegiatan belajar-mengajar secara manual baik itu bahan ajar, soal-soal dan lain sebagainya.

Untuk itulah perlunya guru dan tenaga kependidikan untuk selalu mengikuti pelatihan/bimbingan tentang program-program aplikasi komputer yang dapat menunjang pekerjaannya. Kalau guru diharapkan dapat mengajar dengan baik dan berkualitas melalui perangkat belajar yang telah disiapkannya, kalau tenaga kependidikan diharapkan dapat bekerja dengan baik, cepat, tepat, dan efisien. Adanya pelatihan-pelatihan semacam ini mampu menambah pengetahuan guru dan meningkatkan kompetensi siswa SMK yang nantinya menjadi bekal ketika 


\section{JURNAL CEMERLANG: Pengabdian pada Masyarakat \\ P-ISSN 2654-4741 / E-ISSN 2655-7894 \\ Vol. 2, No. 2, Juni 2020, $121-132$ \\ DOI: https://doi.org/10.31540/jpm.v2i2.817 \\ PENERBIT: LP4MK STKIP PGRI LUBUKLINGGAU}

lulus dan masuk ke dunia kerja (Angriani \& Dayat, 2019). Berdasarkan hasil kuisioner tentang pelaksanaan kegiatan IbM (kegiatan Iptek bagi Masyarakat guru-guru SMA dan MA berbasis pondok pesantren di Kota Jember dalam pembuatan video tutorial pembelajaran), 98\% para guru menyatakan bahwa kegiatan ini adalah kegiatan sangat baik yang seharusnya dilakukan secara berkelanjutan setiap tahunnya (Arif, dkk, 2018). Dari hasil pelaksanaan pengabdian lainnya, output yang diperoleh adalah meningkatnya keahlian guru-guru yang tergabung dalam MGMP Fisika kota Padang dalam memanfaatkan penggunaan software komputer untuk menghasilkan media bahan ajar menggunakan komputer (Ferdian, dkk, 2018).

Sehubungan dengan hal tersebut, Program Studi Pendidikan Matematika Universitas PGRI Palembang ikut peduli dan menindaklanjuti dengan mengadakan kegiatan untuk ikut serta membantu pemerintah dalam meningkatkan pembelajaran yang berkualitas dan perbaikan kerja tenaga kependidikan di sekolah. Dalam upaya tersebut, Program Studi Pendidikan Matematika Universitas PGRI Palembang melaksanakannya dalam bentuk kegiatan Pengabdian Pada Masyarakat (PPM) yang dikemas dalam bentuk bimbingan tentang penggunaan program Visio untuk pembelajaran dan administrasi sekolah. Microsoft Office Visio atau yang biasa disebut Visio adalah sebuah program aplikasi yang sering digunakan untuk membuat Diagram, seperti Diagram alir atau Flowchart. Flowchart (Diagram Alur) digunakan untuk menggambarkan alur/urutan kerja/proses dari sebuah algoritma maupun kejadian tertentu. Diagram alir sendiri biasa digunakan dan dibuat mulai dari kalangan pendidikan untuk kebutuhan tugas dan lain-lain, bahkan dalam dunia kerja pun banyak membuat diagram alir untuk keperluan pekerjaannya, seperti presentasi dan sebagainya. Flowchart dapat juga digunakan perusahaan untuk menggambarkan proses bisnis. Selain membuat diagram alir atau flowchart, Visio juga sangat nyaman untuk pembuatan berbagai macam diagram, brainstorm dan juga beberapa skema jaringan. Aplikasi ini dilengkapi dengan grafik vektor sehingga pengguna lebih 


\section{JURNAL CEMERLANG: Pengabdian pada Masyarakat \\ P-ISSN 2654-4741 / E-ISSN 2655-7894 \\ Vol. 2, No. 2, Juni 2020, $121-132$ \\ DOI: https://doi.org/10.31540/jpm.v2i2.817 \\ PENERBIT: LP4MK STKIP PGRI LUBUKLINGGAU}

mudah dalam pembuatan diagram. Kelebihan yang dimiliki aplikasi ini adalah tools-tools nya sangat mudah dipahami, cara penggunaannya yang mudah, lebih banyak pilihan gambarnya, gambar 3D cukup menarik, bisa ditambah dengan addins. Berikut ini contoh aplikasi program visio yang telah dibuat.

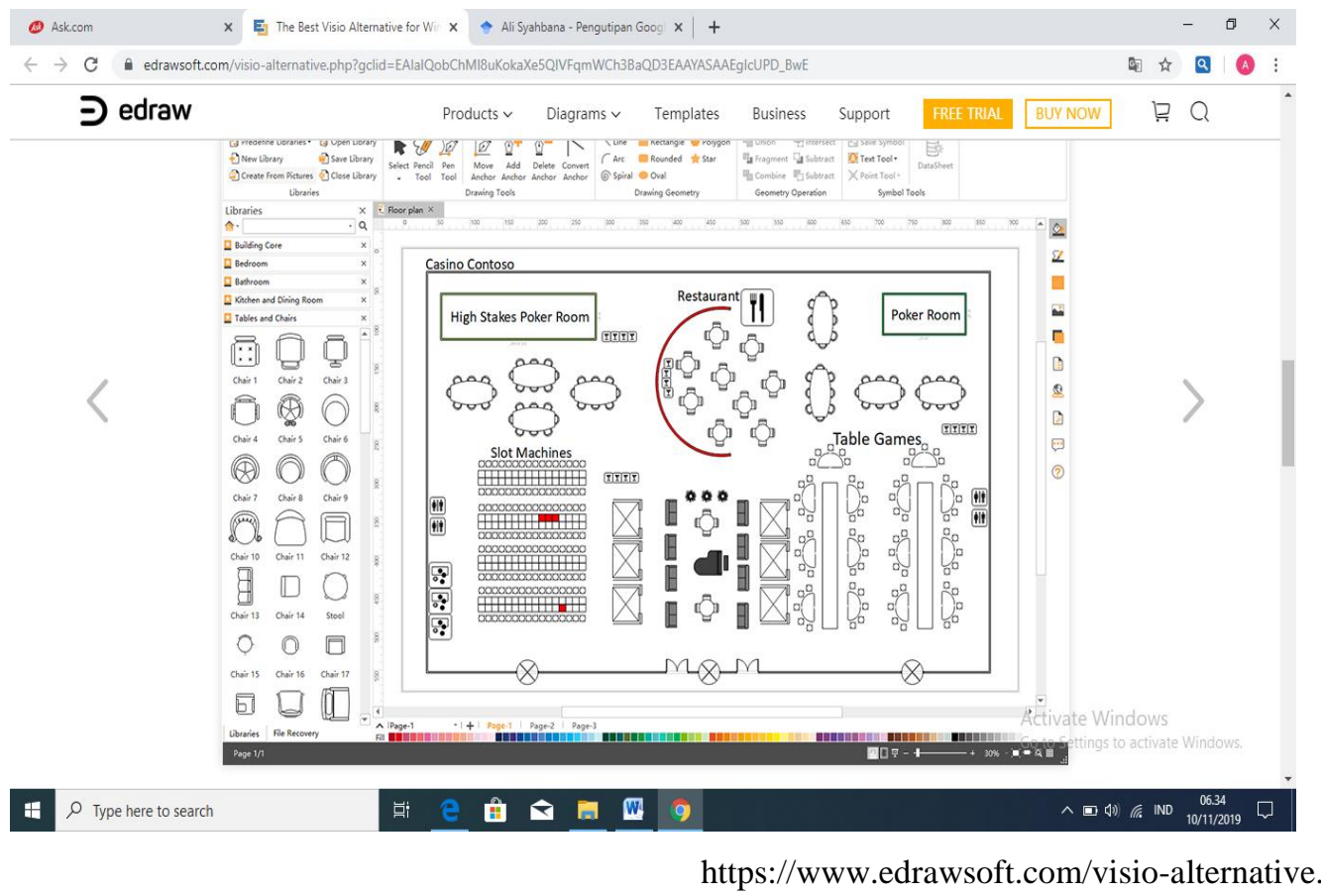

Gambar 1. Contoh aplikasi program visio

\section{METODE}

Kegiatan Pengabdian pada Masyarakat (PPM) ini dilaksanakan di SMK Negeri 1 Gelumbang yang beralamat di Jl. Raya Prabumulih KM 50 Kecamatan Gelumbang Kabupaten Muara Enim Sumatera Selatan. Metode dalam kegiatan Pengabdian ini berupa pelatihan. Pelatihan dilaksanakan selama 1 hari kepada guru dan tenaga kependidikan di sekolah tersebut yang difokuskan untuk mengenalkan penggunaan program aplikasi Visio dalam pembelajaran dan administrasi sekolah.

Tiga tahapan yang dilakukan dalam PPM, yaitu: 1) Persiapan; 2) Pelaksanaan; 3) Refleksi. Masing-masing tahapan dapat diuraikan sebagai berikut: 


\section{JURNAL CEMERLANG: Pengabdian pada Masyarakat \\ P-ISSN 2654-4741 / E-ISSN 2655-7894 \\ Vol. 2, No. 2, Juni 2020, $121-132$ \\ DOI: https://doi.org/10.31540/jpm.v2i2.817 \\ PENERBIT: LP4MK STKIP PGRI LUBUKLINGGAU}

\section{Tahap persiapan}

Beberapa hal yang dilakukan pada tahap ini adalah: identifikasi peserta yang akan mengikuti kegiatan, penyamaan persepsi antar dosen yang akan berperan sebagai narasumber, pemetaan dan penyusunan materi pelatihan, pemilihan dan pembekalan pada mahasiswa yang akan dilibatkan, persiapan sarana dan prasarana (ruang tempat pelaksanaan, perangkat komputer/laptop yang akan digunakan, perangkat lunak Microsoft Visio).

\section{Tahap Pelaksanaan}

Pada tahap ini dilakukan pelatihan kepada guru-guru dan tenaga kependidikan yang ada di lokasi pengabdian. Diawali dengan pengenalan tampilan dan tools-tools yang terdapat pada aplikasi visio. Selanjutnya ditampilkan contohcontoh serta langkah demi langkah penggunaan visio dalam membuat mapping (struktur organisasi dan diagram alir), pembuatan gambar-gambar sederhana, gambar-gambar rumit, Lembar Kerja Siswa (LKS). Setiap dosen menampilkan materi sesuai bagiannya masing-masing. Pada saat tampil, satu orang dosen bertugas sebagai narasumber, menampilkan materi, menunjukkan langkahlangkah pengerjaan menggunakan visio yang setiap langkahnya langsung diikuti oleh peserta pelatihan. Dosen yang sedang tidak menjadi narasumber dengan dibantu dua orang mahasiswa bertugas mendampingi peserta dalam berpraktek, serta memberikan bantuan bila ada peserta yang mengalami kendala atau kesulitan. Proses tanya jawab berlangsung selama penyajian materi. Demikian seterusnya sampai dengan narasumber terakhir menyajikan materinya.

\section{Tahap Refleksi}

Pada tahap ini dilakukan penyebaran angket kepada para peserta guna mengetahui respon peserta terhadap pelaksanaan pengabdian. Selanjutnya juga dilakukan penyusunan laporan hasil pelaksanaan kegiatan pengabdian pada masyarakat. 


\section{JURNAL CEMERLANG: Pengabdian pada Masyarakat \\ P-ISSN 2654-4741 / E-ISSN 2655-7894 \\ Vol. 2, No. 2, Juni 2020, $121-132$ \\ DOI: https://doi.org/10.31540/jpm.v2i2.817

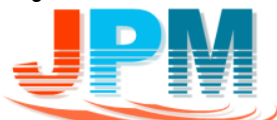 \\ PENERBIT: LP4MK STKIP PGRI LUBUKLINGGAU}

\section{HASIL dan PEMBAHASAN}

Kegiatan PKM berupa pelatihan penggunaan program aplikasi visio untuk pembelajaran dan administrasi sekolah di SMKN 1 Gelumbang telah dilaksanakan dengan baik pada tanggal 9 Mei 2019. Dari kegiatan tersebut telah dihasilkan modul praktikum penggunaan visio yang isinya merupakan gabungan materi yang telah disusun dan disajikan oleh setiap dosen yang menjadi narasumber.

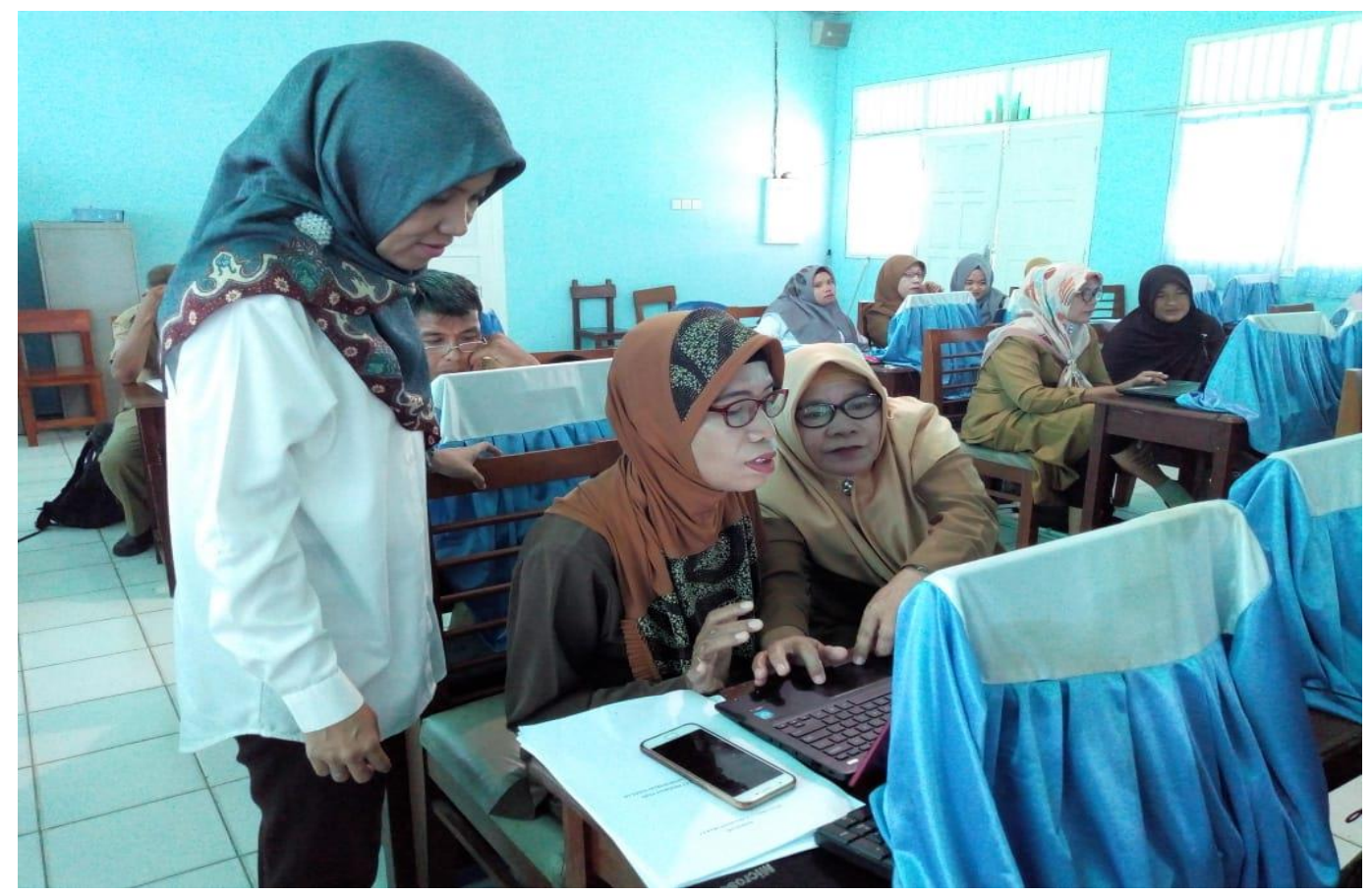

Gambar 2. Dosen membantu guru-guru mempraktekkan materi

Program visio merupakan program aplikasi untuk menggambar. Sebenarnya tool-tool yang ada dalam program banyak kegunaannya dalam keseharian. Namun banyak yang tidak mengetahui. Misalnya dapat untuk membuat struktur organisasi secara lebih baik dan tertata, untuk membuat denah lokasi, membuat gambar pada LKS dan bahan ajar. Gambar-gambar berikut menunjukkan hasil dari praktek langsung di komputer oleh guru dan staf SMK Negeri 1 Gelumbang pada saat pelatihan berlangsung. 

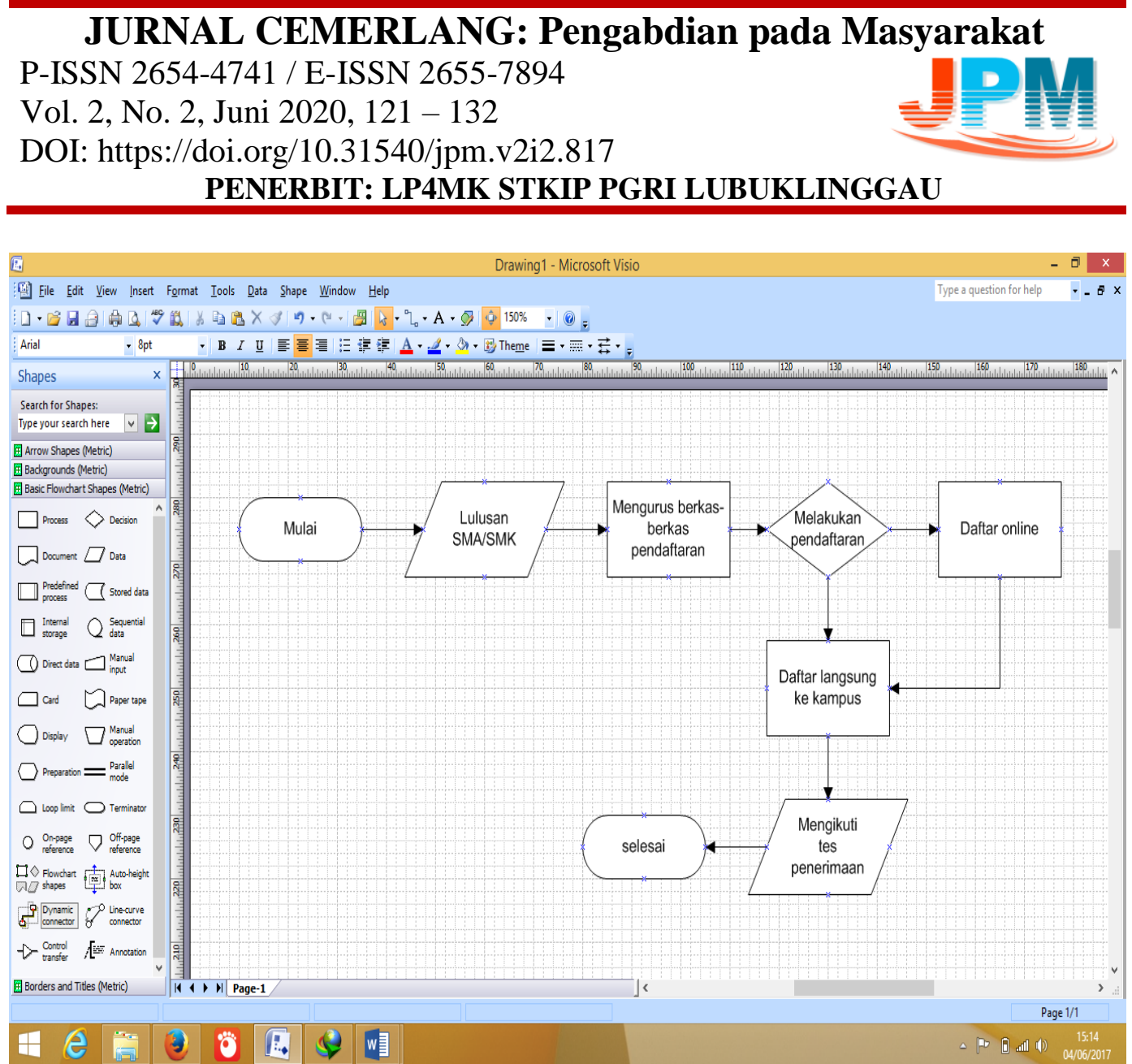

Gambar 3. Pembuatan alur penerimaan mahasiswa baru

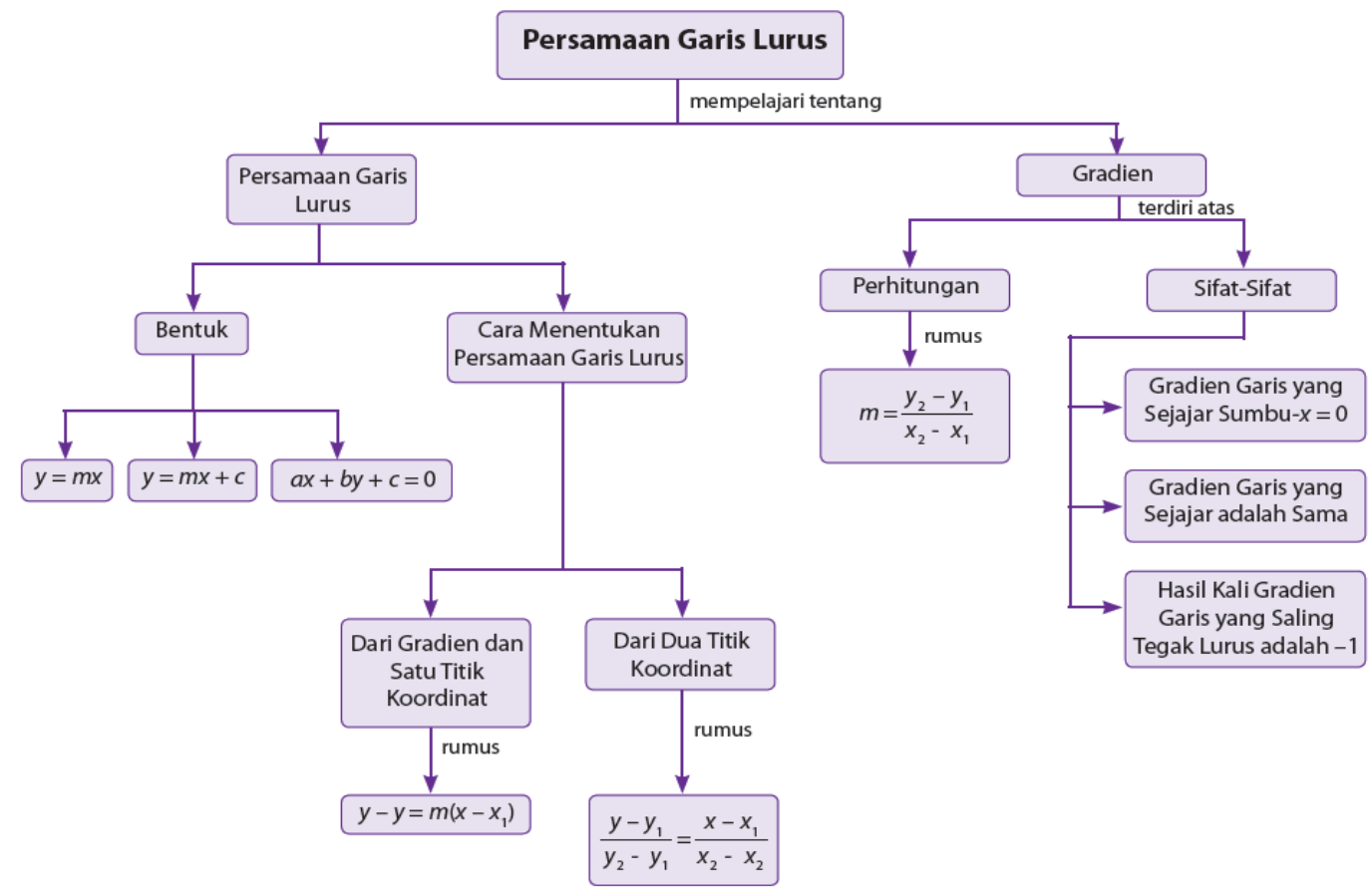

Gambar 4. Pembuatan peta konsep persamaan garis singgung

https://ojs.stkippgri-lubuklinggau.ac.id/index.php/JPM 


\section{JURNAL CEMERLANG: Pengabdian pada Masyarakat}

P-ISSN 2654-4741 / E-ISSN 2655-7894

Vol. 2, No. 2, Juni 2020, 121 - 132

DOI: https://doi.org/10.31540/jpm.v2i2.817

PENERBIT: LP4MK STKIP PGRI LUBUKLINGGAU
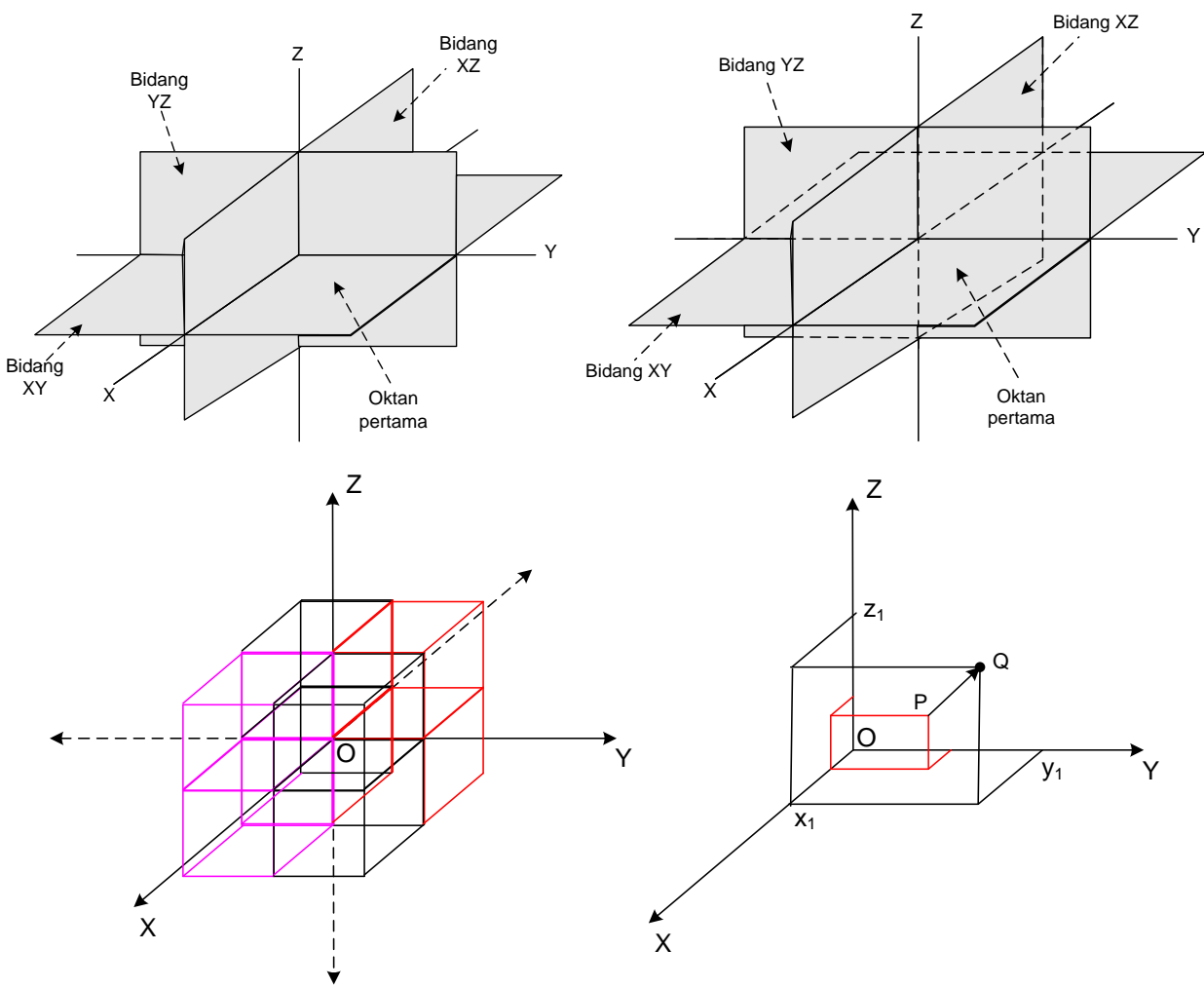

Gambar 5. Pembuatan koordinat kartesius ruang dimensi tiga

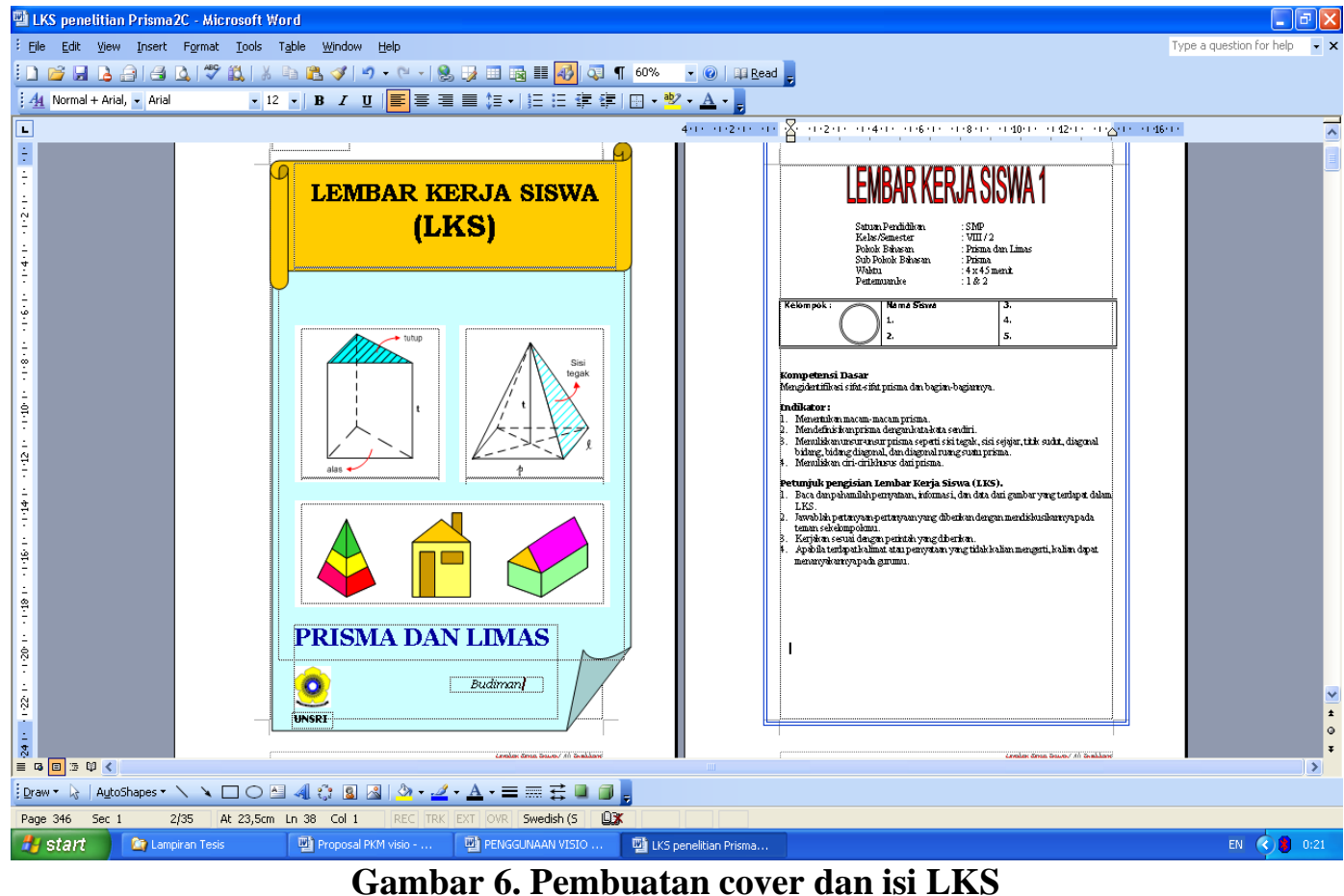

https://ojs.stkippgri-lubuklinggau.ac.id/index.php/JPM 


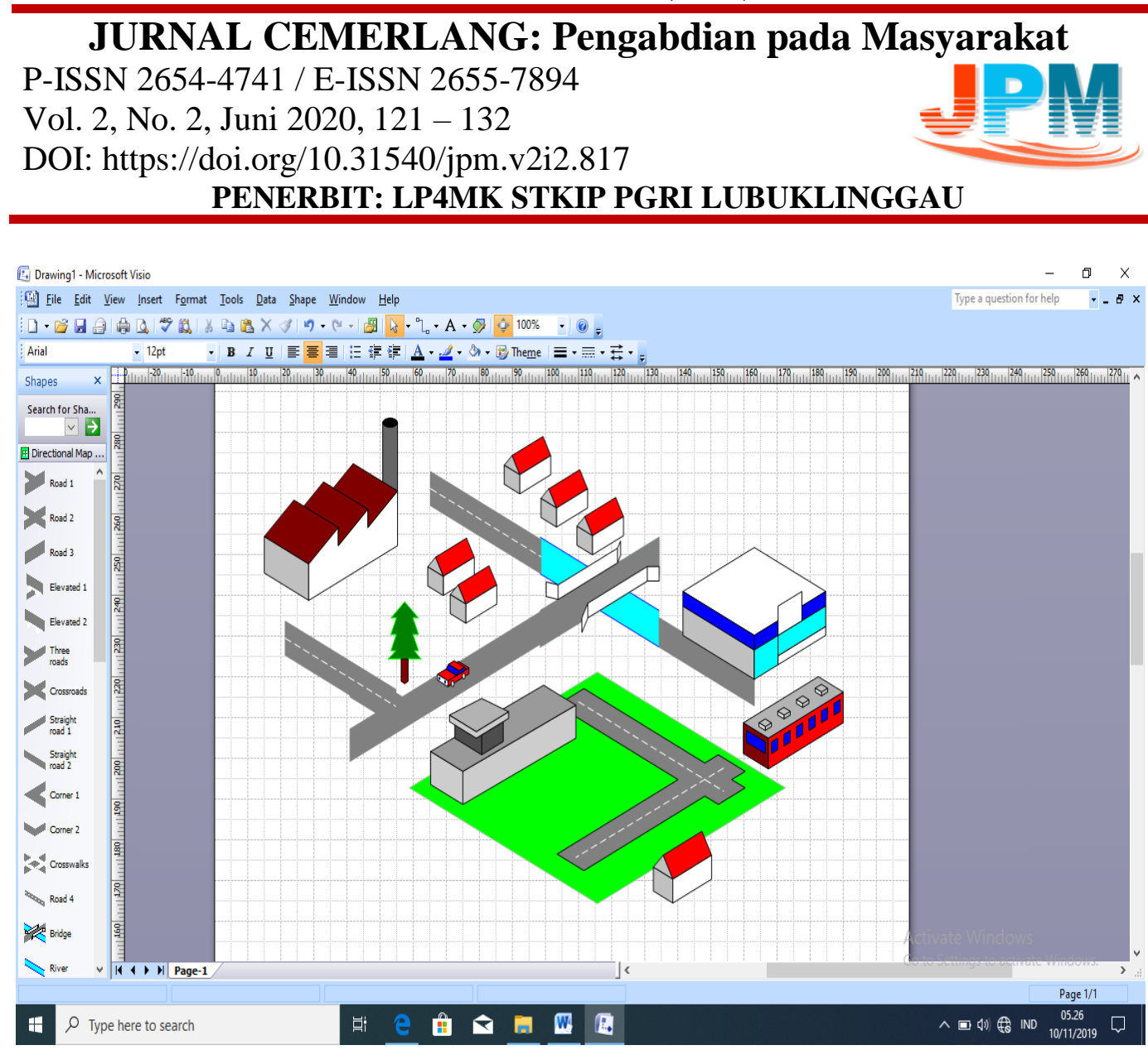

Gambar 7. Pembuatan denah lokasi

Selanjutnya, berdasarkan angket yang telah dibagikan kepada peserta diperoleh hasil bahwa 35,7\% peserta masih merasa kurang lancar menggunakan program visio setelah mengikuti pelatihan, sedangkan $64,3 \%$ peserta sudah merasa lancar. Diperoleh informasi juga 35,7\% peserta menganggap bimbingan yang diberikan instruktur sedang (cukup) dimengerti dan $64,3 \%$ beranggapan mudah dimengerti. Sebanyak 92,9\% peserta beranggapan isi, metode bimbingan serta desain pelatihan sudah memuaskan. Hanya 7,1\% peserta beranggapan masih kurang memuaskan. Untuk pertanyaan terbuka, dimana para peserta diminta menuliskan sendiri berapa persentase materi yang mereka kuasai dari materi yang telah disajikan pada hari itu diperoleh rata-rata 77,6\%. Sebagian besar peserta menjawab $80 \%$ materi yang mereka kuasai, namun ada pula yang menjawab hanya 60\% (1 peserta) dan 1 peserta menjawab 99\% materi dikuasai.

Kritik yang diberikan peserta terhadap pelaksanaan kegiatan PKM ini adalah waktu pelatihan yang terlalu singkat, sehingga peserta berharap kegiatan ini 


\section{JURNAL CEMERLANG: Pengabdian pada Masyarakat \\ P-ISSN 2654-4741 / E-ISSN 2655-7894 \\ Vol. 2, No. 2, Juni 2020, $121-132$ \\ DOI: https://doi.org/10.31540/jpm.v2i2.817 \\ PENERBIT: LP4MK STKIP PGRI LUBUKLINGGAU}

dilaksanakan lagi secara berkala pada waktu berikutnya. Disamping itu juga beberapa peserta berharap lebih banyak lagi contoh yang diberikan, terutama yang langsung terfokus pada kompetensi tiap mata pelajaran.

Tidak ditemui kendala yang berarti selama kegiatan PKM berlangsung. Dari segi teknis mengingat pada kegiatan menggunakan perangkat komputer/laptop dan paparan narasumber menggunakan infocus diharapkan tenaga listrik yang cukup dan tidak mati. Sedangkan dari sisi non teknis, mengingat SMKN 1 Gelumbang terdiri dari 8 jurusan, cukup menyulitkan jika materi yang disusun narasumber harus disesuaikan dengan kompetensi mata pelajaran pada tiap jurusan. Maka dari materi yang disajikan hanya bersifat umum saja dan diharapkan selanjutnya bisa dikembangkan sendiri oleh para peserta sesuai kebutuhan masing-masing.

\section{SIMPULAN}

Kegiatan pelatihan dengan tema "Pelatihan Penggunaan Program Visio Untuk Pembelajaran dan Administrasi Sekolah Di SMKN 1 Gelumbang" merupakan salah satu cara untuk meningkatkan kompetensi guru dan staf administrasi agar menjadi lebih profesional. Berdasarkan hasil angket diperoleh tanggapan yang positif dari para peserta. Oleh karena itu, kegiatan pelatihan sejenis ini sebaiknya terus-menerus dilakukan demi terwujudnya pendidikan yang berkualitas. Mudah-mudahan kegiatan pelatihan ini dapat bermanfaat bagi guruguru dan staf administrasi SMKN 1 Gelumbang dan dapat meningkatkan kemampuan mereka dalam melaksanakan tugasnya.

\section{UCAPAN TERIMA KASIH}

Ucapan terima kasih kami sampaikan kepada pihak Universitas PGRI Palembang yang telah mendanai kegiatan, khususnya Lembaga Penelitian, Pengabdian Kepada Masyarakat (LPPKM) yang telah memfasilitasi kegiatan ini. 


\footnotetext{
JURNAL CEMERLANG: Pengabdian pada Masyarakat

P-ISSN 2654-4741 / E-ISSN 2655-7894

Vol. 2, No. 2, Juni 2020, $121-132$

DOI: https://doi.org/10.31540/jpm.v2i2.817

PENERBIT: LP4MK STKIP PGRI LUBUKLINGGAU
}

\section{DAFTAR PUSTAKA}

Angriani, L. \& Dayat, A.R. (2019). PKM Peningkatan Kompetensi Guru dan Siswa Melalui Pelatihan Pemrograman dan Jaringan Komputer pada Sekolah Menengah Kejuruan di Kota Jayapura. Jurnal Pengabdian kepada Masyarakat ABDIMAS, 23(2), 92-98; https://journal.unnes.ac.id/nju/index.php/abdimas/.

Arif, M.Z., Riski, A., \& Anggraeni, D. (2018). Pengembangan Kualitas Guru-guru SMA dan MA Berbasis Pondok Pesantren Kota Jember Melalui Pelatihan Pembuatan Video Tutorial Pembelajaran. ABDIMAS, 22(1), 27-34

Ferdian, R., dkk. (2018). Laporan Akhir Pengabdian Masyarakat: Pelatihan Gambar Teknik dengan Microsoft Visio bagi Guru MGMP Fisika Kota Padang. http://repo.unand.ac.id/7226/1/Laporan\%20pengabdian\%20masyarakat\%20 MGMP.pdf

Peraturan Menteri Pendidikan Nasional Republik Indonesia nomor 16 tahun 2007. https://npd.kemdikbud.go.id/?appid=rekomendasi.

Wijayanti, I.D. (2011). Peningkatan Pendidikan Berbasis ICT. Yogyakarta: UIN Sunan Kalijaga.

https://www.edrawsoft.com/visio-alternative.php 